\title{
AOR
}

Selected Papers of \#AolR2021:

The 22nd Annual Conference of the

Association of Internet Researchers

Virtual Event / 13-16 Oct 2021

\section{WHITE SUPREMACISTS DECEPTIVELY USING SCREENSHOTS AS EVIDENCE: A SOCIAL SEMIOTIC APPROACH TO ANALYSING CONSPIRATORIAL YOUTUBE VIDEOS}

\author{
Olivia Inwood \\ University of New South Wales

\section{Introduction}

Over the years, extreme right-wing communities have formed on YouTube, spreading discourses of white supremacy and conspiracy. The focus of this study is on the Notre Dame Fire from April 2019, one of the most googled news events of 2019, and an event that ignited hate speech by white supremacists and conspiracists who blamed innocent religious groups and officials for instigating the fire. The dataset for analysis consists of videos taken from popular YouTube videos in English-speaking extreme right-wing communities that spread conspiratorial content about how the fire started or how it was received on social media. Most of these videos also spread disinformation and hate speech by blaming Muslims for starting the fire and labelling the Notre Dame fire as a terrorist act.

Screenshots, defined as a still image that shows the screen of a computer or mobile phone, have become a ubiquitous part of our social media activity, and are often presupposed as evidence to support claims. This study considers the role of screenshots in these conspiratorial YouTube videos and how a social semiotic approach can help to further analyze the social significance of screenshots as a form of evidence. Social semiotics is a perspective on communication that is interested in how language and other modes of meaning-making are used in social contexts. After initially conducting a multimodal analysis on the frames of YouTube videos about the Notre Dame Fire, the high frequency of screenshots appearing as evidence to support conspiratorial claims became apparent. Thus, this initial analysis inspired a more detailed and focused analysis on the specific role of screenshots in these videos. The main questions guiding this study are: what strategies do white supremacists use to artificially create credibility in their conspiratorial YouTube videos? What values are attached to these strategies and how can this be mapped out? 


\section{Literature Review}

Research into screenshots on social media is a relatively new area to explore. Thus, only a few works to-date have considered screenshots as their main object of study. Jaynes (2020) takes an ethnographic approach to analyzing the everyday use of screenshots by teenagers and how screenshots are used as evidence by teenagers. Jaynes (2020: 1378) describes screenshots as a "taken-for-granted practice" but highlights the importance of screenshots as "powerful communicative tools" that should be further studied. Moore (2014:141) has explored digital game screenshots with theories such as cybernetics, remediation, and affect, and writes that in relation to screenshots the digital humanities offers a "powerful and complimentary means for examining the assumptions embedded in their form and function". This highlights the importance of examining screenshots from a social perspective, and the range of methodological contributions that can be made regarding the analysis of screenshots.

In terms of research into screenshots and manipulation, Krafft and Donovan (2020) have analyzed 'evidence collages' in media manipulation campaigns from an ethnographic perspective. These 'evidence collages' consist of screenshots and the authors argue that "the use of visual evidence collages represents a key strategic element in the formation and spread of disinformation" (Krafft and Donovan, 2020). Despite the valuable research that has already been conducted into screenshots, a social semiotic approach in relation to screenshots has not yet been developed. A social semiotic approach would be a valuable addition to research on screenshots, as this approach can systemically provide a way for understanding the social significance of screenshots and how they deceptively contribute to legitimation in discourse.

\section{Methodological Framework}

This study takes a social semiotic approach to understanding screenshots. In particular, this study applies a combined legitimation (Van Leeuwen, 2007) and communing affiliation (Zappavigna and Martin, 2018) framework to the verbal and visual content of 15 videos that were the most viewed conspiratorial videos released about the Notre Dame Fire. The dataset consists of transcripts (20 000 words in total) and frames representing each change of scene in a video (850 images in total). Communing affiliation refers to how values are positioned as bondable in situation where users don't interact directly (Zappavigna and Martin, 2018). It is formed from couplings of ideational (what is being evaluated) and attitudinal (how it is evaluated) meaning as per the appraisal framework (Martin and White, 2005), hence forming a value that is bondable (i.e. a value that can be used to align with others). Legitimation (Van Leeuwen, 2007) refers to how discourses establish or negate authority and can be realized linguistically or visually. There are four main categories of legitimation, and a text can represent multiple (de)legitimations, a single form of (de)legitimation or no (de)legitimation at all. In Table 1 the summarized coding strategy for the data is shown. Overall, a combined communing affiliation and legitimation framework has been considered to understand what values are highlighted in the language and visual content of the videos, and how these values are (de)legitimized or if (de)legitimation is ignored entirely. 


\begin{tabular}{|l|l|l|}
\hline & (De)Legitimation & Communing Affiliation \\
\hline $\begin{array}{l}\text { Verbal } \\
\text { content }\end{array}$ & $\begin{array}{l}\text { Authorization - is authority (de)established via } \\
\text { an authority figure or object? } \\
\text { Moral Evaluation - does (de)legitimation occur } \\
\text { via a value system? } \\
\text { Rationalization - does (de)legitimation occur by }\end{array}$ & $\begin{array}{l}\text { What is being evaluated? (the } \\
\text { ideational target) } \\
\text { How is it being evaluated? } \\
\text { (what type of attitude) } \\
\text { What key social bond is } \\
\text { expressed? }\end{array}$ \\
\hline $\begin{array}{l}\text { Visual } \\
\text { constructed by society? }\end{array}$ & $\begin{array}{l}\text { Mythopoesis - is (de)legitimation expressed by } \\
\text { narratives that reward legitimate actions? }\end{array}$ & $\begin{array}{l}\text { Authorization - is authority (de)established via } \\
\text { an authority figure or object? } \\
\text { Moral Evaluation - does (de)legitimation occur } \\
\text { via a value system? } \\
\text { Rationalization - does (de)legitimation occur by }\end{array}$ \\
$\begin{array}{l}\text { reference to social actions and knowledge } \\
\text { constructed by society? } \\
\text { Mythopoesis - is (de)legitimation expressed by } \\
\text { visual narratives that reward legitimate actions? }\end{array}$ & $\begin{array}{l}\text { What key social bond is } \\
\text { expressed in the visual } \\
\text { content? } \\
\text { Does this key visual bond align } \\
\text { with what is being said (the } \\
\text { language) or is it adding } \\
\text { additional meaning? }\end{array}$ \\
\hline
\end{tabular}

Table 1 - Coding Strategy for Verbal and Visual Data

\section{Key Findings}

Based on preliminary findings, 'technological authority' was a core theme expressed throughout the entire dataset. This 'technological authority' was construed by positive evaluations of video clips and screenshots as evidence in the transcripts, and the use of screenshots as visual evidence. Screenshots were more frequently seen as a form of authorizing legitimation rather than delegitimation. In terms of key bonds, screenshots were used to validate the claims that information is 'valuable', the fire is 'suspicious', migrants are 'evil', video clips are 'truthful', and viewers who watch the channel are 'fearless'. Screenshots in conjunction with language also contributed to 'authorities' and 'Islam' being delegitimized. In other instances, moral evaluations were primarily made through language, rationalizations were made by stating deceptive statistics, and conspiracies were evaluated as valuable by appealing to the idea of a cohesive narrative. A sample of these key bonds and how they relate to legitimation strategies is seen in Figure 1. A sample of the analysis conducted on specific screenshots is shown in Figure 2. 

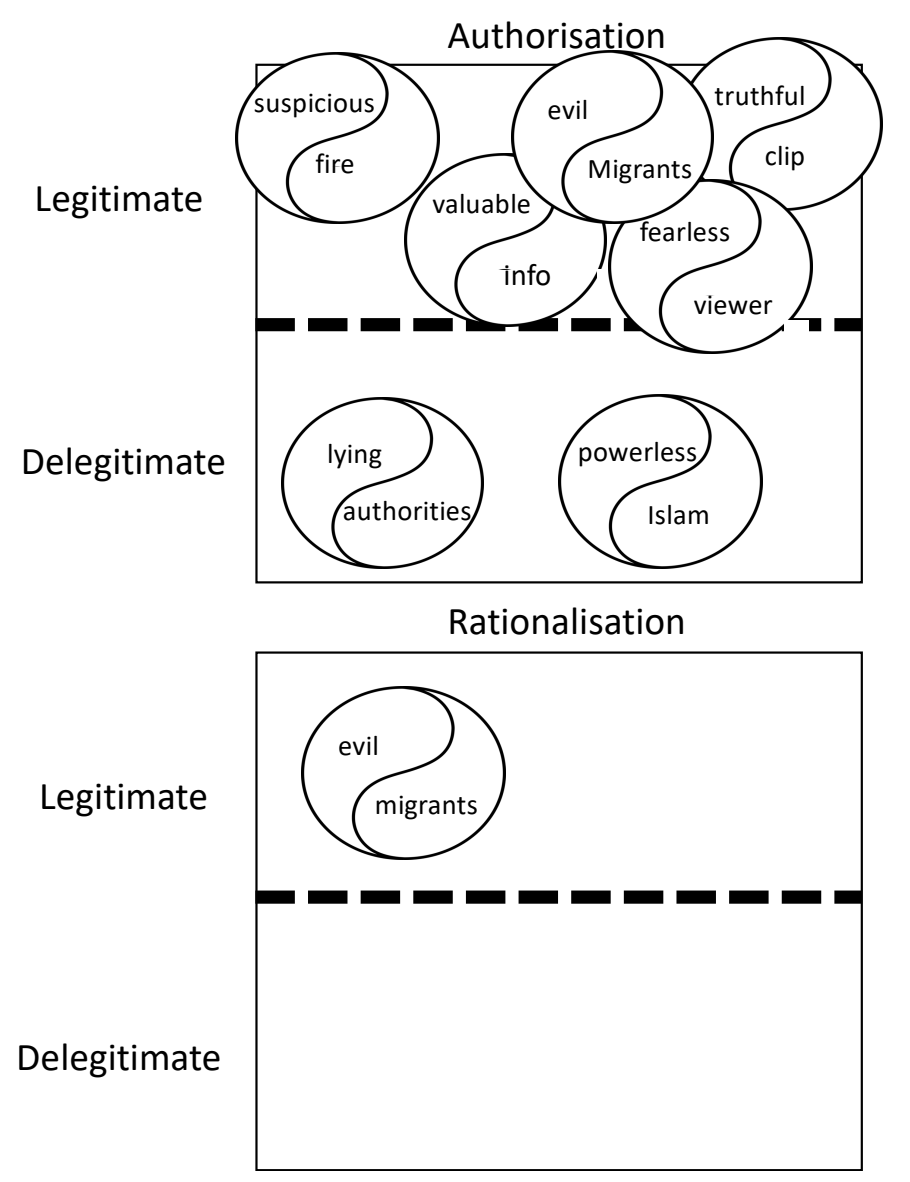
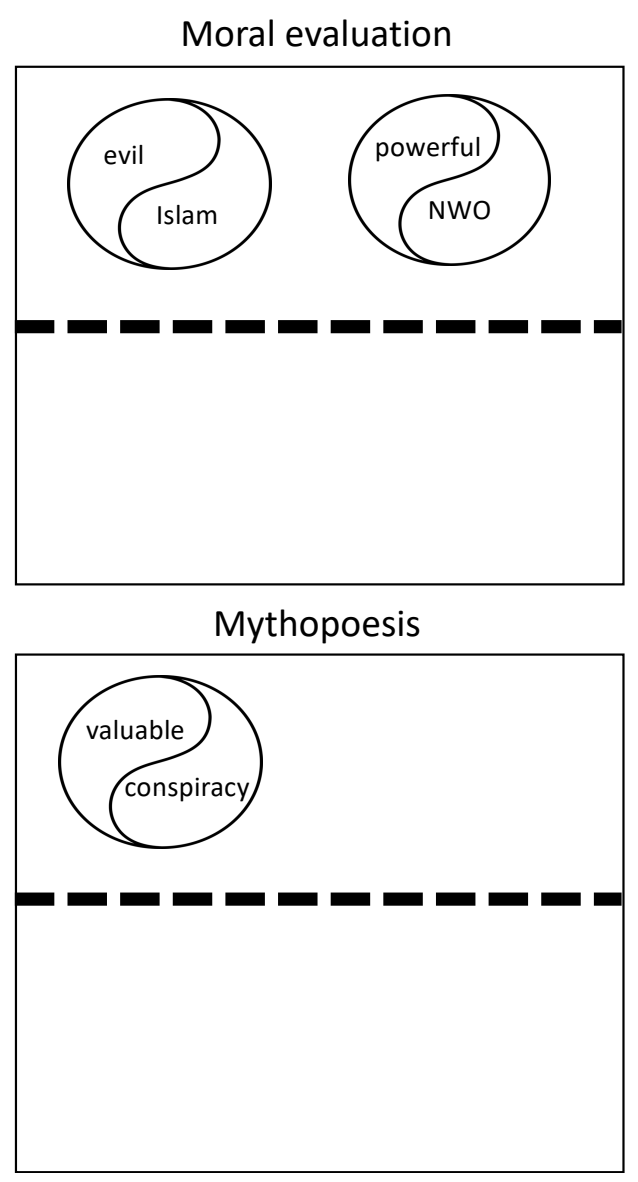

Figure 1 - Sample of the Relationship between Key Bonds and Legitimation Strategies

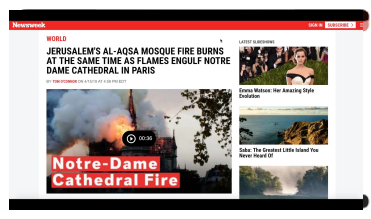

Technological authority

Scrolling through the Newsweek website

Suspicious fire bond

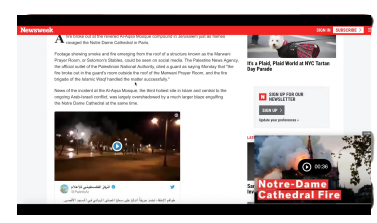

Technological authority

Scrolling through the Newsweek website

Suspicious fire bond
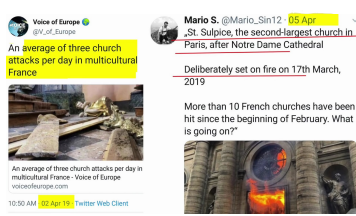

Technological authority

Screenshots from twitter Highlighted text

Suspicious fire bond + Evil Migrants bond

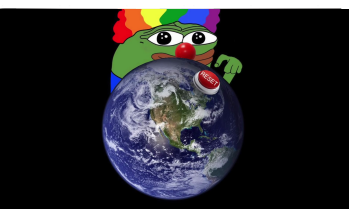

Personal authority

Clown Pepe meme associated with white nationalism + 'name a more toxic community' meme

Fearless viewer bond

Figure 2 - Sample of Specific Screenshots linked to Legitimation and Affiliation Strategies 


\section{Conclusion}

This paper has highlighted how a social semiotic approach can further illuminate the legitimation of screenshots in conspiratorial YouTube videos and the values that they are attached to. Whilst this current study has remained explorative in terms of focusing on new methodological insights rather than providing exact frequencies of how often these features appear, future work will quantify the frequencies of these verbal and visual features across the entire video dataset. YouTube videos can spread conspiratorial and hateful content in sophisticated ways, and screenshots have contributed to the believability and virality of the particular videos discussed in this paper. In other words, the assumption that screenshots solely act as evidence should not be taken for granted and the values and legitimation strategies attached to screenshots needs to be considered. This has several ethical implications for how we independently use screenshots in our daily lives - have we taken for granted screenshots as evidence and ignored the broader social contexts screenshots are implicated in?

\section{References}

Jaynes $V(2020)$ The social life of screenshots: the power of visibility in teen friendship groups. New Media \& Society 22(8): 1378-1393.

Krafft P and Donovan J (2020) Disinformation by Design: The Use of Evidence Collages and Platform Filtering in a Media Manipulation Campaign. Political Communication 37(2): 194-214.

Martin, J. R., \& White, P. R. (2005). The Language of Evaluation: Appraisal in English. London: Palgrave Macmillan.

Moore C (2014) Screenshots as virtual photography. Advancing digital humanities. Springer, pp.141-160.

Van Leeuwen, T. (2007). Legitimation in discourse and communication. Discourse \& Communication, 1(1), 91-112.

Zappavigna, M., \& Martin, J. R. (2018). \# Communing affiliation: Social tagging as a resource for aligning around values in social media. Discourse, Context \& Media, 22, 412. 